\title{
Month of the Year
}

National Cancer Institute

\section{Source}

National Cancer Institute. Month of the Year. NCI Thesaurus. Code C106179.

Any of the 12 major divisions of the year, each lasting approximately 30 days. 